\title{
The dynamics of nurses' authority in the inpatient care of adolescent consumers with anorexia nervosa: a qualitative study of nursing perspectives.
}

\author{
Doctor Joel Sebastian Zugai RN, BN (Hons), PhD
}

Emeritus Professor Jane Stein-Parbury RN, BSN, Med, PhD

Associate Professor Michael Roche RN, DipAppSc, BHSc, MHSc, PhD

\section{Abstract}

Nurses caring for adolescent consumers with anorexia nervosa in the inpatient setting are challenged in a unique way, in that they are caring for people with whom they do not have a mutually held concept of wellbeing. Their efforts to ensure weight gain are frequently against the wishes of the consumer. This dissonance results in challenging interactions, where nursing care and authority may be undermined. This study investigated the dynamics of nurses' authority within this context. Interviews with nurses $(n=10)$ were conducted, and analysed through thematic analysis. Nurses reported that consumers, compelled by the psychopathology of anorexia nervosa, often sought to challenge or undermine their authority. Some nurses experienced the opposition and conflict as demoralising, whereas others were able to maintain confidence in the therapeutic merit of their care. Younger, inexperienced nurses in this study were particularly vulnerable to interactions that mitigated their authority, due to their tendency to engage in friend-like relationships. Nurses caring for adolescents with anorexia nervosa should be prepared to be confronted by interactions that overtly and surreptitiously undermine their capacity to exercise professional authority. 
It is important that nurses recognise the importance of maintaining their authority, and how it can be threatened in subtle and unexpected ways.

Keywords: Anorexia Nervosa, Conflict, Inpatients, Power, Psychiatric Nursing. 


\section{INTRODUCTION}

Akin to the 'rational-legal' authority described by sociologist Max Weber (Giddens 2009), nurses have power by virtue of their professional status and legal endorsement within healthcare organisations. By the nature of their role, nurses occupy a position of power, whilst consumers have an inherently vulnerable position and status (Briant \& Freshwater 1998; Cutcliffe \& Happell 2009; Nursing and Midwifery Board of Australia 2010; World Health Organization 2010). The power differential embedded in the nurse-consumer relationship is liable to result in consumers experiencing coercion in care (Norvoll \& Pedersen 2016). People with Anorexia Nervosa (AN) may need inpatient nursing care when experiencing severe medical complications or psychiatric symptoms (Anderson \& Marks 2017). The inpatient care of people with Anorexia Nervosa AN, whether on involuntary terms or otherwise, frequently involves the exercise of authority (Adlam 2015; Schreyer et al. 2016; Tan et al. 2010).

In the context of inpatient care for people with AN, nurses deliver care with compassion and empathy, supporting consumers with the distressing task of weight gain. However, drawing on their authority, nurses also provide an ongoing supervisory and authoritative presence, instructing consumers in accordance with prescribed eating and exercise regimes. In the event that a consumer's health and safety is threatened, nurses may be required to exercise their authority by delivering care that is not necessarily consented to by the consumer, for example, in the administration of involuntary nasogastric feeding (Bakker et al. 2011; Zugai, Stein-Parbury \& Roche 2013). The inpatient care of people with AN then involves a well-tempered balance of 
interpersonal care, as well as the capacity for authoritative intervention (Zugai, SteinParbury \& Roche 2018b).

Nursing care that involves non-negotiable actions or force, limiting consumer autonomy, is frequently referred to as coercion. O’Brien and Golding $(2008$, p.168) define coercion in mental health nursing as "any use of authority to override the choices of another". The term authority is used here, as this term is more representative of the nursing capacity for such an approach, rather than its enactment. Nurses employ their authority based on an underlying assumption that doing so is ultimately performed in the overall best interests of the person for whom they are caring (Hem et al. 2018; Vuckovich \& Artinian 2005). This study will explore nurses' perception of their authority in caring for consumers with AN.

\section{Background}

AN is a serious mental disorder, with a reported incidence rate of eight per 100,000 per year, with 15-19 years old girls a particularly high risk group (Hoek 2006; Smink, van Hoeken \& Hoek 2012). People with AN value and strive for thinness (Gregertsen, Mandy \& Serpell 2017), and frequently die prematurely in the pursuit (Arcelus et al. 2011; Keshaviah et al. 2014); people with AN have a standardised mortality ratio of 5.86 (Arcelus et al. 2011), and are 18 times more likely to die by suicide compared to gender and age matched groups (Smith, Zuromski \& Dodd 2018). Effective care, particularly for those who require the intensity of an inpatient admission, is a clear priority for consumers with AN. In the inpatient setting, nurses have a pivotal role in the delivery of care to the most acutely ill people with AN. 
Nurses caring for consumers with AN face a unique challenge, in that they are caring for a person with whom they are not likely to share a common concept of wellbeing. This discordance is particularly apparent in the acuity of the inpatient setting, as consumers with AN struggle with the intense anxiety and ambivalence that weight gain evokes. Consequently, consumers with AN may engage in activities that subvert weight gain. In understanding this behaviour, it is necessary to acknowledge that consumers with AN experience internal turmoil and distress from weight gain throughout hospitalisation (Fennig et al. 2017). Nurses then experience challenges when delivering care that is not necessarily agreed to by the consumer. The complexities of exercising authority are particularly challenging when caring for adolescents with AN.

Exercising authority in the care of adolescent consumers with AN must be undertaken with caution. Compared to adult consumers, adolescents with AN are liable to experience a greater sense of coercion in care (Guarda et al. 2007). Adolescent consumers are also more likely to experience coercion when admitted involuntarily or cared for against their will (Nyttingnes et al. 2018), a common feature of adolescent inpatient AN care. Furthermore, nurses who exercise authority in the inpatient mental healthcare of adolescents are themselves liable to experience guilt, frustration and moral distress, as they perceive an inconsistency between their clinical duties and their own personal moral standards (Matthews \& Williamson 2016). The way that nurses use their power has clear potential for harm to consumers, as well as nurses themselves. 
The conflict between the psychopathological implications of AN and the nurse's professional responsibility is resolved by nurses' capacity to develop an effective therapeutic interpersonal relationship with the consumer, whilst concurrently maintaining a clear objection to AN; nurses demonstrate care and compassion for the individual consumer, whilst also tactfully employing their authority to ensure weight gain (Zugai, Stein-Parbury \& Roche 2018a). Although the judicious application of authority is crucial, little is understood about the unique challenges that nurses experience in maintaining and managing their authority in the care of adolescent consumers with AN. The dynamics of nursing authority within this specific context are ambiguous and complex: unravelling these will enable nurses to understand the prudent use of their legitimate power.

\section{Aim}

The aim of this study was to explore the dynamics of nurses' authority with adolescent consumers who are being treated for AN in the inpatient setting.

\section{METHODS}

\section{Design}

This study investigated complex social interactions between nurses and consumers that are not well understood. For this reason, a qualitative, exploratory approach was apposite (Andrews, Sullivan \& Minichiello 2004). This paper reports on a subset of data from a larger study reported elsewhere (Zugai, Stein-Parbury \& Roche 2018a, 2018b). Data for this study were collected between May 2014 and February 2015. The first listed author (JZ) conducted all data collection as a PhD student, a role clearly specified 
in the information sheets provided to participants. JZ has previously led qualitative research investigating nursing care of people with AN (Zugai, Stein-Parbury \& Roche 2013). Other than as a researcher, JZ had no employment or previous relationship with the sites or participants.

\section{Setting and Participants}

Employing purposive, non-probability sampling, nurses $(n=10)$ were recruited from two wards, within two public hospitals in Sydney, Australia. Purposive, non-probability sampling was appropriate to obtain data from a specific population with specific experiences (Llewellyn, Sullivan \& Minichiello 2004). In these wards, nurses routinely cared for adolescent consumers with AN with a program of care tailored for the needs of people with AN. The wards were not devoted mental health wards, nor were they specifically devoted to the care of people with AN. Participating nurses were either Registered Nurses or Enrolled Nurses. Only one nurse had a specific mental health nursing qualification.

\section{Procedure}

Nurses were recruited following completion of a paper-based survey (the results of which are reported elsewhere) that offered them the opportunity to indicate their willingness to participate in an interview. Information forms were provided to nurses who expressed interest, and written consent was obtained. The interviews took place at a time and location of participants' choice, outside of work hours. Nurses opted to be interviewed at their workplace in a private location, one nurse was interviewed by telephone. Nurses were interviewed with a semi-structured format, which provided 
flexibility to explore various themes whilst also maintaining a focused interview (Minichiello et al. 2004). Interviews were ceased at the point of data saturation, when no new themes or ideas arose (Fusch \& Ness 2015; Llewellyn, Sullivan \& Minichiello 2004). Interviews were recorded and later transcribed.

\section{Ethics}

This study was approved by both university and health service human research ethics committees. Informed written consent was obtained prior to all interviews.

Participants were assured that their contributions would remain non-identifiable, and pseudonyms were attributed to participants' responses accordingly.

\section{Data Analysis}

The audio files were listened to and the transcripts were read multiple times to immerse the principal investigator in the data. The data were interpreted through a thematic analysis, whereby recurring themes are attributed significance (Browne 2004). Coding was employed to aid the interpretation and organisation of data. The process of developing and assigning codes to interview data aided in the identification of recurring themes, and aided in the thematic categorisation of quotes. Coding is a suitable approach for research where participants' responses are guided by a semistructured interview format (Morse 2015). In presenting the research findings, quotes are used to support the interpretation of the data.

\section{RESULTS}

Table 1 provides details of the participants in relation to nursing experience in years and designation. The sample was variable in composition, with experience in nursing 
care for people with eating disorders ranging from six months to twenty-eight years.

The sample consisted of three Enrolled Nurses (EN) and seven Registered Nurses (RN). Of the RNs, three were in senior management and/or education roles. On average, interviews lasted 45 minutes.

Conveying the complex dynamics of nursing authority, two over-arching themes were developed from the thematic analysis: 'The path of most resistance', and 'The friendzone'. Each overarching theme had three sub-themes, as illustrated in Table 2.

The path of most resistance: nurses' authority and consumers' opposition This theme is focused on the way that consumers responded to nursing authority, and the implications of this response for nursing staff. According to the participants, consumers frequently responded to nurses' authority with opposition. The opposition that nurses experienced led some nurses to feel insecure in relation to their nursing role. Conversely, other nurses who were confident in the merit of their authority, maintained certainty of their role.

\section{Authority and opposition}

In accordance with the rules of the eating disorder program, nurses in this study were responsible for exercising their authority in order to assist consumers with weight gain. At times this nursing responsibility led to nurses receiving criticism and hostility from consumers.

And there have been occasions where they've not wanted me to look after them because, again, it gets back to the fact that I follow the program and I don't let 
them swap food. I'm just all the nitty-gritty about the rules... So, they don't like it. And I'm sure if they had their choices, they'd never see me again (Beverley).

Nurses who delivered care with close adherence to the rules of the eating disorder program experienced consumers' openly expressed criticism. At an extreme, consumers attempted to negate the authority of these rigorous nurses with requests for staff reallocation. Brenda was one such nurse who was meticulous in applying the rules of the eating disorder program.

Sometimes they will ask, "Can I have this nurse," or "Can I have that nurse." ... I look at the other nurses who they "like" and who they "don't like" and I'm not alone. I know there's a couple of other staff who they'll blatantly bad mouth to other staff (Brenda).

By fulfilling their role with scrupulous adherence to the eating disorder program rules, nurses were liable to evoke the anxieties of consumers, which sometimes led to consumers' expressed frustration. Regardless of therapeutic motives, nurses who exercised their authority experienced consumers' opposition.

\section{Role conflict}

Nurses understood that weight gain was inherently distressing for consumers, and that nursing activities that involved use of authority strained therapeutic relationships and interactions; some nurses felt that their responsibility to exercise authority against the consumer's will conflicted with their interpersonal nursing role. 
And I think that's probably why it's so difficult sometimes and that we are the baddies. We enforce these rules that make them put on weight, so that obviously puts a big strain on the relationship... But particularly with these girls, I think it does put a big strain because you're asking them to do something that for them is so hard to comprehend (Kara).

The description of nurses as 'baddies' is an acknowledgement of consumers' perception of nurses as a coercive archetype. Some nurses were susceptible to the demoralisation that came with being seen as a forcible figure.

I was constantly at war with myself and then also with them. Knowing what I need to do in my role as a registered nurse and as a healthcare provider to help them... I couldn't just say, "No, it has to happen." I'd try and talk them into it and be nice and try and get them to come to the realisation that they need it when they were never going to come to that conclusion on their own; you had to forcefully tell them, "You need to do this." So it was quite agonising (Cassandra).

Cassandra felt uncomfortable acting authoritatively, compelling consumers to engage in care by means of firm instruction. Cassandra's struggle with her position of power was compounded by the conflict between her aspiration to be an effective registered nurse, whilst also being validated by the appreciation of those she cared for.

That is one of my probably key problems at the moment; I want to be liked (Cassandra). 


\section{Professional authority and confidence}

Some nurses did not experience the conflict that distressed Cassandra. These nurses did not seek validation from consumers, and instead sought satisfaction from delivering appropriate care. These nurses managed their authority with greater ease and certainty.

If a patient decides that they're going to like me, then that's fine. If a patient decides they're not going to like me, I still have a job to do and I'm still expected to do the job. So, it's an advantage if they like me, but I still do my job if they don't (Beverley).

As I said earlier, they don't like me; there are a certain couple of long-term patients who make that quite obvious. They have asked the team leader if they can swap nurses. They haven't made a complaint or anything like that, but just that I'm strict and they don't like that. So, I think - I often hear a groan or a sigh when I come in in the mornings .... But at the end of the day, they don't hate me. They don't - well, I don't think they do. But I think it does have an effect. And then you just kind of get on with it, you don't - it's not personal (Brenda).

Even despite overt criticisms from consumers, these nurses remained confident in their role as a nurse, and assured in their use of authority.

\section{The friend-zone: the challenge of young nurses}

The authority of young nurses was challenged in unique ways. Consumers interacted with young nurses in a way that resembled friendship and this led to permeable professional boundaries, which threatened nurses' capacity to exercise their authority. 
The relative inexperience of younger nurses warranted the close supervision by senior nursing staff.

\section{Nurses' age and authority}

A number of participants were aged in their twenties, and these nurses suffered a unique challenge to their authority. These nurses felt that they were placed into a friend-like category by consumers, and consequently were less able to exert their authority. Common interests and ease of interactions shared by consumers and younger nurses aided the transition of the nurse to a peer.

So, a lot of the girls are-or quite a few-are mid to later teens, like $15,14,16$. And I'm 22 so we can kind of relate more than, say, the nurses that are in their 40s or 50s. And they're kind of- it's easier to make friends with people your own age. You're like, "Oh, yeah, I was just in school," "Oh, yeah, I've done this," "I've done that," going through the same experiences pretty much. And then, of course, all the nurses that are older also have the more experience - well, generally - have the more experience and able to create those boundaries. I think it's more of shared experiences with age (Cassandra).

Some of them see you as an equal or they think of you as their friend as opposed to a nurse (Millie).

Obviously, I'm closer in age to these kids, so I can probably relate more to other things other than diet and whatever else they talk about... It made it harder to implement rules.... sometimes it's harder to implement rules because they see you as more of their friend rather than a nurse" (Kara). 
In these types of relationships, nurses felt uncertain and uneasy in exercising their authority. As a result, professional boundaries became blurred.

\section{Blurred professional boundaries}

According to the nurses interviewed, the imposition of a friend-like role led to blurred professional boundaries. Consumers had expectations towards nurses that resembled those that are shared with their peers. Consumers expected nurses to negate their authority, and participate in social activities outside of the professional spectrum.

On phones they'll video themselves, like, just being girls and doing all these exercise videos or even creating things about them being fat, creating songs about the eating disorder program, about them being fat, about the ways in which they try and like - not abuse the program - like get around the program, like emptying their feeds and watering them down. They put these all in songs and that, and then they show it to you and like, "Ah-ha-ha, isn't it funny? Don't tell anyone." ... they kind of latch onto that friendship that they have formed with you, thinking like, "We're friends. I'm going to show you, and you're not going to tell anyone. So, you we can get away with it because you think I'm your friend rather than your nurse" (Cassandra).

I wouldn't like a patient to get attached. I've had patients trying to friend me on Facebook and I've had them try to follow me on Instagram. And so, that's where I worry (Millie).

Knowing that such interactions with consumers were a breach of professional boundaries, these nurses felt awkward and uncomfortable. 


\section{Inexperience}

The challenges that junior nurses experienced were considered at least partially attributable to a lack of both life and clinical experience. An experienced clinical nurse consultant $(\mathrm{CNC})$ commented on the difficulties that inexperienced nurses had in applying their newly acquired authority.

If the nurses are a new grad or they're someone who's closer in age to the patients, they don't have the life experience. They find it much more difficult to set limits and follow through with consequences. So, it's really important that we target new grads or new people coming to work in the ward and mentor them and give them the skills to be able to put those limits into place (Marilyn).

The clinical nurse educator (CNE) from the same ward commented on the increased supervision that young, inexperienced nurses needed to effectively care for consumers with AN.

We don't send the new staff members straightaway. And we also make sure that not young staff member goes there. If they are young but they are matured then it's different thing but if they are young and not matured, we don't send them. [...That is] Because the person - the staff is not confident themselves and it affects their treatment... The patient won't have confident and trust in the new staff person, and staff is not confident as well (Caroline).

Both the CNC and the CNE were clear about their concerns in relation to junior nurses. Owing to their inexperience, junior nurses needed focused attention from senior staff to ensure that they were prepared to exert authority. 


\section{Discussion}

Recovery from $\mathrm{AN}$ is a lengthy process, involving a multi-dimensional restoration. In reaching clinical milestones of recovery from AN, consumers secure physical, cognitive and psychological health, and overcome behavioural pathology (Bardone-Cone, Hunt \& Watson 2018). Recovery from AN also involves intangible elements, such as the development of positive relationships with others, self-acceptance and autonomy; a renewed sense of purpose, meaning and spiritual integration may also be part of consumers' recovery journey (de Vos et al. 2017). In assisting consumers with overcoming AN, nurses in this study utilised their capacity to exercise authority in order to secure the requisite condition for these aspects of wellbeing: a weight compatible with health and recovery. The results of this study demonstrate how nurses' authority is susceptible to complex obstacles in the inpatient care of adolescents with AN.

The opposition that nurses experienced when exercising their authority had implications for the way that nurses perceived themselves. For some nurses, opposition from consumers led to an insecure sense of professional identity. This study, as well as previous studies, demonstrated how nurses caring for consumers with AN perceive themselves as a coercive form of authority. In exercising professional authority, nurses are liable to perceive themselves as a jailer, police officer or sergeant major (King \& Turner 2000; Ramjan 2004). These paternalistic archetypes of coercive authority are a departure from the caring and helpful nursing identity, a profession dependent on interpersonal skills and human connection (Stein-Parbury 2018). Nurses in this study were frustrated by their perceived failure to fulfil their own idealised 
concept of a nurse, and questioned the therapeutic merit of their role. Subsequently, nurses felt demoralised and conflicted (King \& Turner 2000; Snell, Crowe \& Jordan 2010).

Consumers' open opposition towards nurses is likely a manifestation of the distress that consumers experience from re-feeding and weight gain (Zugai, Stein-Parbury \& Roche 2018b); and, also may be an overt attempt to re-establish power. Some nurses in this study felt uncomfortable with exercising their authority, due to the opposition that they were liable to receive. The discomfort or hesitation that some nurses experienced when exercising their authority is undoubtedly noticed by consumers. At the risk of receiving consumers' condemnation, the guilt and insecurity felt by some nurses meant they were less likely to exercise their authority. Other nurses in this study were not vulnerable in this way, and were confident in their role, even despite consumers' opposition. These nurses acknowledged that consumers' opposition was a response to treatment stressors and should not be interpreted as a personal or professional affront. This form of internal resolution has been previously described (King \& Turner 2000; Snell, Crowe \& Jordan 2010). With this understanding, nurses exercised their professional authority with confidence, certain of the therapeutic merit of their actions.

Nurses of a younger age in this study experienced a unique obstacle. The authority of young nurses was hindered by their tendency to engage in friend-like interactions with consumers. This style of interaction may not be suitable in the care of consumers with $\mathrm{AN}$, as friendships usually involve equal and negotiable distribution of power. In the 
context of inpatient care for consumers with AN, the development of a friend-like relationship may impair nurses' necessary use of authority. The tendency of friend-like relationships to develop is attributable to a number of factors. Contrary to the way that consumers tend to respect the authority of a nurse who appears to be of a maternalistic age (Zugai, Stein-Parbury \& Roche 2018a), younger nurses are perceived by adolescent consumers as an object of friendship. Aiding friend-like interactions further still, young nurses are accustomed to friendships, and find comfort in the predictability of this kind of relationship (Stein-Parbury 2018). Furthermore, the role distress that some nurses experienced when exercising their authority may also tempt young nurses to engage in a friend-like relationship, in order to avoid the demoralisation of being perceived as a coercive authority. Ironically, attempts to preserve a 'therapeutic relationship' through friend-like interactions can undermine the capacity of the nurse to deliver appropriate care.

Destabilisation of nursing authority should be recognised as a manifestation of the psychopathology of AN, rather than an activity that consumers should be held culpable for. When physical control over intake (food) and output (exercise) is suspended, consumers with AN are compelled by their illness to opt for strategies to counter weight gain. Indeed, protective behaviours were previously described by Boughtwood \& Halse (2010), who noted they may include subtle activities, such as the way that consumers decorate personal spaces in hospital.

The complex dynamics of nurses' authority in adolescent AN care are attributable to the discordant goals of nurses and consumers. Consumers struggle to trust the 
therapeutic intent of nurses who are attempting to facilitate weight gain. In turn, nurses may struggle to care for people with goals that stand in stark opposition to conventional concepts of wellbeing. This state of perpetual opposition and mistrust is unlike other nursing situations. Nurses are not accustomed to being mistrusted by the people for whom they care (Brenan 2017; Roy Morgan 2017; Skinner \& Clemence 2017), resulting in the complex challenges reported in this study. In order to care for consumers with AN, nurses need specialised training and support. Young, inexperienced nurses in particular need to be supported to maintain therapeutic professional boundaries. Preceptorships are particularly important in this regard (Davies \& Willsher 2012).

Though the results of this study caution against interactions that are akin to those exchanged in a friendship, an interpersonally conservative nursing approach is not recommended. That is, to be aloof or detached from consumers is not conducive to interpersonally sound nursing care. Adolescents who have received care for AN place value on interpersonal supportive relationships with healthcare professionals (Salzmann-Erikson \& Dahlén 2017; Sibeoni et al. 2017). Establishment of the therapeutic alliance is a fundamental activity in mental health nursing (Zugai, SteinParbury \& Roche 2015), and the development of a therapeutic alliance is an important aspect of care when working with people who have AN, with implications for outcomes (Zaitsoff et al. 2015). An effective approach to the care of people with AN requires a balance of both interpersonal engagement, and authority; nursing people with AN involves an applied balance of 'love and limits' (Zugai, Stein-Parbury \& Roche 2018a). 


\section{Research Limitations}

This study is limited by its relatively small, heterogenous sample size. No male nurses were interviewed for this study. Male nurses' authority may be experienced differently by consumers. The nurses in this study cared only for adolescent consumers with AN. Future research should consider the perspectives of nurses and consumers in adult settings, such as involuntary mental health units, as adult consumers are liable to experience nursing authority differently from adolescents. The opposition that nurses experienced may be largely attributable to the nature of adolescence, rather than AN, and this has not been controlled for in this study.

\section{Conclusions}

Nursing care of adolescent consumers with AN is complex, as nurses struggle to care for an individual with whom they are not likely to share a common concept of wellbeing. The means by which consumers subvert weight gain are not limited to physical efforts, such as the compromise of food intake and furtive exercise. As a consequence of AN, anxiety driven behaviours are likely to manifest in order to mitigate that which gives nurses the capacity to ensure weight gain: authority.

\section{Relevance for Clinical Practice}

This study highlights how nurses' position of power can be readily threatened. Nurses must be cautious of the nature of their interactions, so that their capacity to fulfil their duties remains intact. The interactions that disempowered nurses were subtle, indicating the importance of nurses' overall awareness of appropriate boundaries. In this study, nurses' capacity for therapeutic use of power was threatened by 
interactions that placed self-interest ahead of consumer's health needs. It is the observance of professional boundaries that maintains the fidelity of the powerdifferential; professional boundaries ensure that the relationships between nurses and consumers are focused on the health-related needs of consumers (Griffith 2013; Valente 2017). This study also demonstrates the importance of close supervision for young, inexperienced nurses. Young, inexperienced nurses will benefit from education and support focused on their preparation for the subtle interactions that threaten their capacity to exercise authority for therapeutic effect. The findings of this have wider relevance, in that the findings are applicable in settings where nurses may rely on authority to deliver care, such as in the context of involuntary care. 


\section{References}

Adlam, J. 2015, 'Refusal and coercion in the treatment of severe Anorexia Nervosa: The Antigone paradigm', Psychodynamic Practice, vol. 21, no. 1, pp. 19-35.

Anderson, G. \& Marks, P. 2017, 'Eating Disorders', in K. Evans, D. Nizette \& A. O'Brien (eds), Psychiatric and Mental Health Nursing, 4th edn, Elsevier, Chatswood, NSW.

Andrews, I., Sullivan, G. \& Minichiello, V. 2004, 'The philosophical and theoretical context of qualitative research', in V. Minichiello, G. Sullivan, K. Greenwood \& R. Axford (eds), Research methods for nursing and health science, 2 edn, Pearson, Prentice Hall, Frenchs Forest, NSW, pp. 59-70.

Arcelus, J., Mitchell, A.J., Wales, J. \& Nielson, S. 2011, 'Mortality rates in patients with anorexia nervosa and other eating disorders', Arch Gen Psychiatry, vol. 68, no. 7, pp. 724-31.

Bakker, R., van Meijel, B., Beukers, L., van Ommen, J., Meerwijk, E. \& van Elburg, A. 2011, 'Recovery of normal body weight in adolescents with anorexia nervosa: the nurses' perspective on effective interventions', Journal of Child and Adolescent Psychiatric Nursing, vol. 24, no. 1, pp. 16-22.

Bardone-Cone, A.M., Hunt, R.A. \& Watson, H.J. 2018, 'An Overview of Conceptualizations of Eating Disorder Recovery, Recent Findings, and Future Directions', Current Psychiatry Reports, vol. 20, no. 9.

Boughtwood, D. \& Halse, C. 2010, 'Other than obedient: Girls' constructions of doctors and treatment regimes for anorexia nervosa', Journal of Community \& Applied Social Psychology, vol. 20, no. 2, pp. 83-94.

Brenan, M. 2017, Nurses keep healthy lead as most honest, ethical profession, Gallup, Washington, D.C., viewed 10th of June 2018, <http://news.gallup.com/poll/224639/nurses-keep-healthy-lead-honest-ethicalprofession.aspx?g source=Economy\&g medium=newsfeed\&g campaign=tiles $>$.

Briant, S. \& Freshwater, D. 1998, 'Exploring mutuality within the nurse-patient relationship', British Journal of Nursing, vol. 7, no. 4, pp. 204-11.

Browne, J. 2004, 'Grounded theory analysis: coming to data with questioning minds', in V. Minichiello, G. Sullivan, K. Greenwood \& R. Axford (eds), Handbook of research methods for nursing and health science, 2nd edn, Pearson, Prentice Hall, Frenchs Forest, NSW, pp. 624-73.

Cutcliffe, J. \& Happell, B. 2009, 'Psychiatry, mental health nurses, and invisible power: Exploring a perturbed relationship within contemporary mental health care: Feature Article', International Journal of Mental Health Nursing, vol. 18, no. 2, pp. 116-25.

Davies, J. \& Willsher, M. 2012, 'Professional boundaries when working with adolescents', British Journal of Nursing, vol. 21, no. 17, pp. S23-4, S7-8, S30.

de Vos, J.A., LaMarre, A., Radstaak, M., Bijkerk, C.A., Bohlmeijer, E.T. \& Westerhof, G.J. 2017, 'Identifying fundamental criteria for eating disorder recovery: A systematic review and qualitative meta-analysis', Journal of Eating Disorders, vol. 5, no. 1.

Fennig, S., Brunstein Klomek, A., Shahar, B., Sarel-Michnik, Z. \& Hadas, A. 2017, 'Inpatient treatment has no impact on the core thoughts and perceptions in adolescents with anorexia nervosa', Early Intervention in Psychiatry, vol. 11, no. 3, pp. 200-7.

Fusch, P.I. \& Ness, L.R. 2015, 'Are we there yet? Data saturation in qualitative research', Qualitative Report, vol. 20, no. 9, pp. 1408-16.

Giddens, A. 2009, 'Politics, government and social movements', in A. Giddens (ed.), Sociology, 6th edn, Polity, Massachusetts, USA, pp. 985-1027.

Gregertsen, E.C., Mandy, W. \& Serpell, L. 2017, 'The egosyntonic nature of anorexia: An impediment to recovery in anorexia nervosa treatment', Frontiers in Psychology, vol. 8, no. DEC. 
Griffith, R. 2013, 'Professional boundaries in the nurse-patient relationship', British Journal of Nursing, vol. 22, no. 18, pp. 1087-8.

Guarda, A.S., Pinto, A.M., Coughlin, J.W., Hussain, S., Haug, N.A. \& Heinberg, L.J. 2007, 'Perceived coercion and change in perceived need for admission in patients hospitalized for eating disorders', American Journal of Psychiatry, vol. 164, no. 1, pp. 108-14.

Hem, M.H., Gjerberg, E., Husum, T.L. \& Pedersen, R. 2018, 'Ethical challenges when using coercion in mental healthcare: A systematic literature review', Nursing Ethics, vol. 25, no. 1 , pp. 92-110.

Hoek, H.W. 2006, 'Incidence, prevalence and mortality of anorexia nervosa and other eating disorders', Current Opinion in Psychiatry, vol. 19, no. 4, pp. 389-94.

Keshaviah, A., Edkins, K., Hastings, E.R., Krishna, M., Franko, D.L., Herzog, D.B., Thomas, J.J., Murray, H.B. \& Eddy, K.T. 2014, 'Re-examining mortality in anorexia nervosa: a metaanalysis redux', Comprehensive Psychiatry, vol. 55, no. 8, pp. 1773-84.

King, S.J. \& Turner, D.S. 2000, 'Caring for adolescent females with anorexia nervosa: registered nurses' perspective', Journal of Advanced Nursing, vol. 32, no. 1, pp. 139-47.

Llewellyn, G., Sullivan, G. \& Minichiello, V. 2004, 'Sampling in qualitative research', in V. Minichiello, G. Sullivan, K. Greenwood \& R. Axford (eds), Handbook of research methods for nursing and health science, 2nd edn, Pearson, Prentice Hall, Frenchs Forest, NSW, pp. 210-41.

Matthews, H. \& Williamson, I. 2016, 'Caught between compassion and control: Exploring the challenges associated with inpatient adolescent mental healthcare in an independent hospital', Journal of Advanced Nursing, vol. 72, no. 5, pp. 1042-53.

Minichiello, V., Madison, J., Hays, T. \& Parmenter, G. 2004, 'Doing qualitative in-depth interviews', in V. Minichiello, G. Sullivan, K. Greenwood \& R. Axford (eds), Handbook of research methods for nursing and health science, 2nd edn, Pearson, Prentice Hall, Frenchs Forest, NSW, pp. 411-46.

Morse, J.M. 2015, 'Critical analysis of strategies for determining rigor in qualitative inquiry', Qual Health Res, vol. 25, no. 9, pp. 1212-22.

Norvoll, R. \& Pedersen, R. 2016, 'Exploring the views of people with mental health problems' on the concept of coercion: Towards a broader socio-ethical perspective', Social Science and Medicine, vol. 156, pp. 204-11.

Nursing and Midwifery Board of Australia 2010, A nurse's guide to professional boundaries, Nursing and Midwifery Board of Australia, Melbourne, Victoria.

Nyttingnes, O., Ruud, T., Norvoll, R., Rugkåsa, J. \& Hanssen-Bauer, K. 2018, 'A cross-sectional study of experienced coercion in adolescent mental health inpatients', BMC Health Services Research, vol. 18, no. 1.

O'Brien, A.J. \& Golding, C.G. 2003, 'Coercion in mental healthcare: The principle of least coercive care', Journal of Psychiatric and Mental Health Nursing, vol. 10, no. 2, pp. 16773.

Ramjan, L.M. 2004, 'Nurses and the 'therapeutic relationship': caring for adolescents with anorexia nervosa', Journal of Advanced Nursing, vol. 45, no. 5, pp. 495-503.

Roy Morgan 2017, Roy Morgan Image of Professions Survey 2017: Health professionals continue domination with Nurses most highly regarded again; followed by Doctors and Pharmacists, Roy Morgan, 7244.

Salzmann-Erikson, M. \& Dahlén, J. 2017, 'Nurses' establishment of health promoting relationships: a descriptive synthesis of anorexia nervosa research', Journal of Child and Family Studies, vol. 26, no. 1, pp. 1-13.

Schreyer, C.C., Coughlin, J.W., Makhzoumi, S.H., Redgrave, G.W., Hansen, J.L. \& Guarda, A.S. 2016, 'Perceived coercion in inpatients with Anorexia nervosa: Associations with illness 
severity and hospital course', International Journal of Eating Disorders, vol. 49, no. 4, pp. 407-12.

Sibeoni, J., Orri, M., Colin, S., Valentin, M., Pradère, J. \& Revah-Levy, A. 2017, 'The lived experience of anorexia nervosa in adolescence, comparison of the points of view of adolescents, parents, and professionals: A metasynthesis', International journal of nursing studies, vol. 65, no. 1, pp. 25-34.

Skinner, G. \& Clemence, M. 2017, Politicians remain the least trusted profession in Britain, Ipsos MORI, viewed 10th of June 2018, <https://www.ipsos.com/ipsos-mori/enuk/politicians-remain-least-trusted-profession-britain $>$.

Smink, F.R.E., van Hoeken, D. \& Hoek, H.W. 2012, 'Epidemiology of Eating Disorders: Incidence, Prevalence and Mortality Rates', Current Psychiatry Reports, vol. 14, no. 4, pp. 406-14.

Smith, A.R., Zuromski, K.L. \& Dodd, D.R. 2018, 'Eating disorders and suicidality: what we know, what we don't know, and suggestions for future research', Current Opinion in Psychology, vol. 22, pp. 63-7.

Snell, L., Crowe, M. \& Jordan, J. 2010, 'Maintaining a therapeutic connection: nursing in an inpatient eating disorder unit', Journal of clinical nursing, vol. 19, no. 3-4, pp. 351-8.

Stein-Parbury, J. (ed.) 2018, Patient \& Person: Interpersonal Skills in Nursing, 6th edn, Elsevier, Chatswood, N.S.W.

Tan, J.O.A., Stewart, A., Fitzpatrick, R. \& Hope, T. 2010, 'Attitudes of patients with anorexia nervosa to compulsory treatment and coercion', International Journal of Law and Psychiatry, vol. 33, no. 1, pp. 13-9.

Valente, S.M. 2017, 'Managing professional and nurse-patient relationship boundaries in mental health', Journal of Psychosocial Nursing and Mental Health Services, vol. 55, no. 1, pp. 45-51.

Vuckovich, P.K. \& Artinian, B.M. 2005, 'Justifying coercion', Nursing Ethics, vol. 12, no. 4, pp. $370-80$.

World Health Organization 2010, Mental Health and Development: Targeting people with mental health conditions as a vulnerable group, WHO Press, Geneva, Switzerland.

Zaitsoff, S., Pullmer, R., Cyr, M. \& Aime, H. 2015, 'The Role of the Therapeutic Alliance in Eating Disorder Treatment Outcomes: A Systematic Review', Eating Disorders, vol. 23, no. 2, pp. 99-114.

Zugai, J., Stein-Parbury, J. \& Roche, M. 2013, 'Effective nursing care of adolescents with anorexia nervosa: a consumer perspective', Journal of Clinical Nursing, vol. 22, no. 1314, pp. 2020-9.

Zugai, J.S., Stein-Parbury, J. \& Roche, M. 2015, 'Therapeutic alliance in mental health nursing: An evolutionary concept analysis', Issues in Mental Health Nursing, vol. 36, no. 4, pp. 249-57.

Zugai, J.S., Stein-Parbury, J. \& Roche, M. 2018a, 'The nature of the therapeutic alliance between nurses and consumers with Anorexia Nervosa in the inpatient setting: A mixed-methods study', Journal of Clinical Nursing, vol. 27, no. 1-2, pp. 416-26.

Zugai, J.S., Stein-Parbury, J. \& Roche, M. 2018b, 'Therapeutic alliance, anorexia nervosa and the inpatient setting: A mixed methods study', Journal of Advanced Nursing, vol. 74, no. 2, pp. 443-53. 
Table 1: Participant Demographics

\begin{tabular}{|c|c|c|c|}
\hline Nurse & Nursing Experience & Eating Disorder & Designation \\
\hline (pseudonym) & (Years) & $\begin{array}{l}\text { Nursing Experience } \\
\text { (Years) }\end{array}$ & \\
\hline Cassandra & 0.5 & 0.5 & RN \\
\hline Millie & 5 & 5 & RN \\
\hline Beverley & 32 & 11 & EN \\
\hline Brenda & 2 & 0.5 & RN \\
\hline Kara & 0.5 & 0.5 & RN \\
\hline Kathleen & 1 & 1 & EN \\
\hline Christine & 24 & 13 & RN \\
\hline Marilyn & 35 & 28 & $\mathrm{RN}$ \\
\hline Caroline & 13 & 12 & RN \\
\hline Tracey & 7 & 7 & EN \\
\hline
\end{tabular}


Table 2: Themes

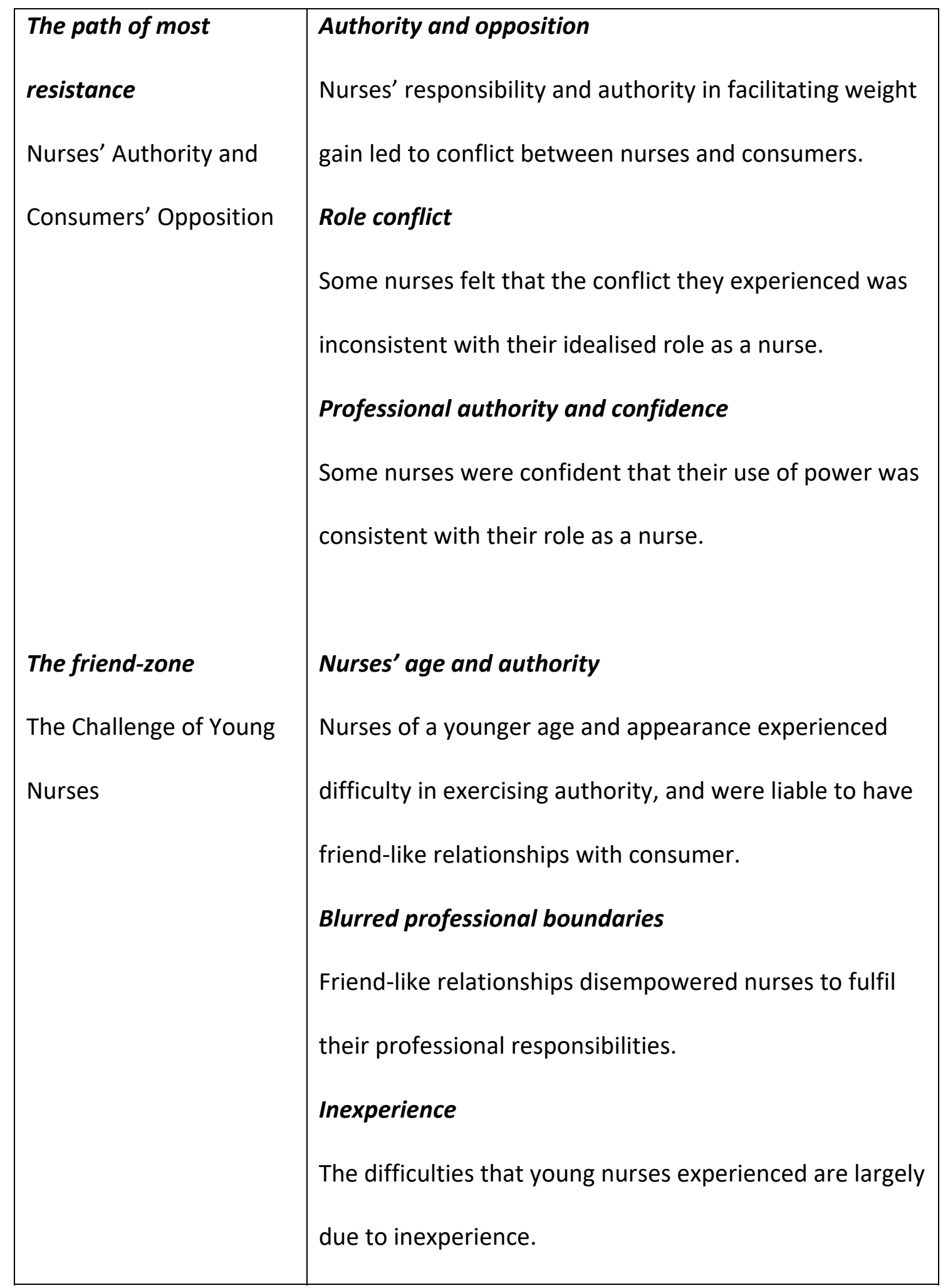

